\title{
VIVÊNCIAS DE PRAZER-SOFRIMENTO NO TRABALHO DO PROFESSOR UNIVERSITÁRIO: ESTUDO DE CASO EM UMA INSTITUIÇÃO PÚBLICA
}

\author{
Elena Fátima Vilela \\ elena.vilela@gmail.com \\ Faculdade Novos Horizontes - Belo Horizonte, MG / Brasil \\ Fernando Coutinho Garcia \\ garciafc.bh@terra.com.br \\ Faculdade Novos Horizontes - Belo Horizonte, MG / Brasil \\ Adriane Vieira \\ vadri.bh@gmail.com \\ Universidade Federal de Minas Gerais - Belo Horizonte, MG / Brasil
}

Recebido em 16/02/2011

Aprovado em 08/12/2012

Disponibilizado em 01/08/2013

Avaliado pelo sistema double blind review

Revista Eletrônica de Administração

Editor: Luís Felipe Nascimento

ISSN 1413-2311 (versão on-line)

Editada pela Escola de Administração da Universidade Federal do Rio Grande do Sul.

Periodicidade: Quadrimestral

Sistema requerido: Adobe Acrobat Reader.

\section{RESUMO}

Este artigo analisa as percepções dos professores do curso de pedagogia de uma instituição de ensino superior pública em relação ao prazer-sofrimento no trabalho docente, amparado na teoria da Psicodinâmica do Trabalho. A pesquisa foi realizada na Faculdade de Educação de uma Universidade Pública de Belo Horizonte. Trata-se de um estudo conduzido por meio de técnicas de coleta e análise de dados de natureza quantitativa e qualitativa, utilizando a Escala de Indicadores de Prazer-sofrimento no trabalho (EIPST), aplicada a 52 professores, e a entrevista semiestruturada, realizada com 9 professores. Os dados quantitativos foram tratados pelo sistema SPSS (Statistical Package for Social Science) e as entrevistas foram submetidas à análise de conteúdo. Os resultados indicaram que as vivências de prazer são predominantes e estão relacionadas ao orgulho e à identificação com o trabalho. As vivências de sofrimento ocorrem de forma moderada e estão relacionadas ao esgotamento, à sobrecarga de trabalho e ao estresse, além de sentimentos de indignação e desvalorização. Como forma compensatória do sofrimento, as vivências de prazer são maximizadas e têm origem na prática docente, no contato com os colegas de trabalho e os alunos, na produção de conhecimento e no reconhecimento advindo dos pares e da comunidade.

Palavras-chave: prazer; sofrimento; professor; adoecimento; universidade. 
Vivências de prazer-sofrimento no trabalho do professor universitário: estudo de caso em uma instituição pública

\section{EXPERIENCES INVOLVING PLEASURE-SUFFERING AT THE UNIVERSITY TEACHERS ENVIRONMENT: CASE STUDY AT A PUBLIC INSTITUTION}

This article aims at analyzing the perceptions of the professors of the pedagogy courses in a public university in relation to pleasure-suffering while teaching, based on theory of Psychodynamics at Work. The research was carried at the education school of a public university in Belo Horizonte. It is a case study which was carried by collection and data analysis of quantitative and qualitative nature by using the Scales of Pleasure-Suffering Indicators at work (EIPST) applied to 52 professors and the semi-structured interview performed by 9 professors. The quantitative data were treated with by the system SPSS (Statistical Package for Social Science) and the interviews were analyzed according to their content. The results indicated that the pleasure experiences are predominant and are also related to the pride and to the identification of the work. The suffering experiences occurred in a moderate way and are related to the nervous breakdown, overwork and stress, besides the feelings of indignation and depreciation. As a compensation of the suffering, the pleasure experiences are maximized and have its origin in the teaching practice, in a close contact with the workmates and students, in the production of knowledge and in the recognition that comes from the pairs and from the community as well.

Keywords: Pleasure; Pain; Professor; Disease; University.

\section{INTRODUÇÃO}

O trabalho do professor universitário vem passando por transformações profundas, em consequência da economia de mercado global e do surgimento de novas tecnologias, que propiciam a incorporação de novas e contínuas exigências à atividade docente. Nas universidades públicas, o impacto dessas mudanças se faz sentir pela intensificação do trabalho do professor, uma vez que essas instituições assumem os mesmos pressupostos ditados pela economia de mercado.

Segundo Chauí (2003), a educação passou a compor o setor de serviços não exclusivos do Estado, deixando de ser concebida como um direito. Definida como organização, a universidade tornou-se operacional, segundo a autora, regida por contratos de gestão, avaliada por índices de produtividade e calculada para ser flexível. Ela está estruturada por estratégias e programas de eficácia organizacional e, portanto, pela particularidade e instabilidade dos meios e objetivos.

O novo modelo gerencial adotado pelas instituições públicas de ensino superior reproduziu no âmbito universitário as características próprias do trabalho flexível, impondo uma nova lógica às rotinas acadêmicas e influenciando o trabalho docente. Segundo Mancebo (2007), as consequências deste novo modelo de universidade pública se refletem na prática e na organização do trabalho docente, mediante a intensificação de suas atividades e o estímulo à produtividade, sendo causa de doenças físicas e psíquicas, manifestas ou sublimadas pelas 
contradições do contexto de trabalho, nos quais os professores vivenciam a um só tempo o prazer e o sofrimento advindos da prática docente.

Esta pesquisa foi realizada com professores do curso de Pedagogia da Faculdade de Educação de uma universidade pública de Belo Horizonte, Minas Gerais. Teve por objetivo analisar as percepções de prazer-sofrimento dos docentes no exercício da profissão. Para cumprir este objetivo, investigaram-se a relação que se estabelece entre a dinâmica prazer-sofrimento no trabalho e os sintomas físicos e psicossociais relacionados ao trabalho.

A coleta de dados se deu por meio de técnica quantitativa e qualitativa. Foram ouvidos 9 professores por meio de entrevista semiestruturada e 52 professores, de uma população de 115, responderam a um questionário baseado no Inventário de Trabalho e Riscos de Adoecimento (ITRA), desenvolvido e validado em estudos de Mendes e Ferreira (2007). A coleta aconteceu durante o mês novembro de 2009, nas instalações da Faculdade e em sala reservada para a pesquisa, de forma a garantir a privacidade dos envolvidos e o sigilo das informações.

$\mathrm{Na}$ sequência deste artigo, apresentam-se o referencial teórico que deu suporte à análise dos dados, o detalhamento da metodologia de pesquisa, a análise e descrição dos dados coletados e as considerações finais.

\section{PRAZER E SOFRIMENTO NO TRABALHO DOCENTE}

A abordagem psicodinâmica do trabalho foi desenvolvida por Christophe Dejours, na França, a partir dos estudos da psicopatologia do trabalho, iniciados em 1980, quando o autor passou a direcionar seus estudos e pesquisas para a normalidade, deslocando a análise das doenças mentais para a análise das estratégias individuais e coletivas dos trabalhadores contra o sofrimento e as doenças mentais decorrentes da sua atividade laboral.

A partir daquela data, o campo da pesquisa em psicopatologia foi ampliado, buscando-se esclarecer como homens e mulheres conseguem driblar a doença mental, apesar das pressões organizacionais. Apoiando-se na teoria psicanalítica, Dejours (1987) introduziu o conceito de sublimação, mostrando que existem saídas bem-sucedidas para o conflito entre a organização do trabalho e o sujeito do desejo. Dejours (2007) concluiu, também, que a normalidade é uma conquista que resulta da criação de estratégias individuais e coletivas de defesa dos trabalhadores no que se refere ao sofrimento no trabalho. Suas pesquisas buscaram analisar os motores psíquicos e sociais do prazer no trabalho, realizando importantes descobertas sobre a inteligência 
Vivências de prazer-sofrimento no trabalho do professor universitário: estudo de caso em uma instituição pública

do corpo, a engenhosidade e a psicodinâmica do reconhecimento, que permitem transformar o sofrimento em prazer, conferindo sentido e valor a ele (DEJOURS, 2007).

O termo psicodinâmica do trabalho passou a existir a partir de 1993, para definir o amplo domínio da clínica, sendo mais abrangente que psicopatologia. Segundo Dejours (2007), a partir desse momento, a psicopatologia passou a se inserir no campo da psicodinâmica do trabalho, contemplando as descompensações que surgem quando as estratégias de defesa são comprometidas por um sofrimento que o sujeito não consegue contornar, tornando-se autodestrutivo. Além do sofrimento, a psicodinâmica passou a se interessar pelo prazer no trabalho e pela diferença entre o trabalho prescrito e o trabalho real (DAVEZIES, 1991; BRANDT, DEJOURS, DUBAR, 1995). Essa passagem teve consequências práticas e teóricas, pois a psicopatologia do trabalho aparecia implicitamente como disciplina especializada no campo das ciências da saúde e, naturalmente, dedicada à análise, à superação e, eventualmente, ao tratamento das doenças mentais (DEJOURS, 1993).

Ao propor a normalidade como objeto de estudo, a psicodinâmica do trabalho abriu caminho para perspectivas mais amplas, que não abordam apenas o sofrimento, mas também o prazer no trabalho; não somente o homem, mas também o trabalho; e não somente a organização do trabalho, mas também as situações de trabalho nos detalhes de sua dinâmica interna (DEJOURS, 2008). Não se trata de estudar as doenças mentais descompensadas ou os trabalhadores por ela atingidos, mas sim todos os trabalhadores, enfim, a população real e "normal" que está nas fábricas, nas usinas e nos escritórios, a qual é submetida a pressões no seu dia a dia. O objeto de estudo passou a ser não a loucura, mas o sofrimento no trabalho, um estado compatível com a normalidade e que implica uma série de mecanismos de regulação.

De acordo com Lhuilier (2007), articulada à sociologia compreensiva, à psicanálise e à ergonomia, a psicodinâmica do trabalho entende o sujeito no trabalho como um ser que age e se constrói nessa interação. Gernet e Dejours (2009) esclarecem que trabalhar significa defrontar-se com prescrições, procedimentos e instrumentos a serem manipulados, ao mesmo tempo em que é preciso interagir com a hierarquia organizacional e com colegas e acolher ou cuidar de pessoas para atingir o objetivo de produzir um bem ou um serviço. Por este motivo, segundo os autores, a definição do trabalho não pode se limitar à descrição da atividade individual. $\mathrm{O}$ trabalho é sempre uma relação social, a qual envolve um conjunto de relações entre o sujeito e aqueles com e para quem ele trabalha, a fim de coordenar as inteligências singulares (RENAULT, 2008). 
A dialética prazer/sofrimento do trabalho docente remonta ao contexto histórico do desenvolvimento da profissão e está diretamente relacionada à valorização social da categoria. Oliveira e Freitas (2008) afirmam que a profissão docente surgiu sob a tutela da Igreja e foi passada à tutela do Estado com o advento da República. Assim, ao longo da história, consolidouse a imagem da docência como sacerdócio, apostolado, que deveria ser exercida com humildade, paciência e obediência, pois se constituía em uma atividade conduzida por sujeitos remunerados e controlados pelo Estado.

Entre as causas do mal-estar docente se podem assinalar: carência de tempo suficiente para realizar um trabalho decente; dificuldades dos alunos; aumento da carga horária; trabalho burocrático, que rouba tempo da tarefa de ensinar e que se transforma em fadiga; descrença no ensino como fator de modificações básicas das aprendizagens dos alunos; e modificação no conhecimento e nas inovações sociais como desafios que provocam grande ansiedade e sentimento de inutilidade (ESTEVE, 1987; COLE e WALKER, 1989; GOMES, 1993; MARTÍNEZ e KOHEM, 1997; STOBAUS e MOSQUERA; SANTOS, 2007).

Como forma de enfrentar o sofrimento psíquico, os professores desenvolvem estratégias singulares de defesa, como: excessiva submissão; resistência a todo tipo de mudança; baixo índice de envolvimento com o trabalho; psicossomatização; e perda de percepção e consciência dos sérios problemas vivenciados no cotidiano da escola (OLIVEIRA, 2006).

Segundo Freitas (2007), a academia é hoje um lugar de risco para a saúde, pela frequência das doenças psicossomáticas entre professores. Entre os males mais diagnosticados citam-se: gastrite, taquicardia, hipertensão, irritabilidade, insônia, depressão, síndrome do pânico, estresse e síndrome do esgotamento profissional (burnout). Com excessão da sala de aula e do relacionamento com os alunos, fatores considerados gratificantes, cobranças excessivas, compressão do tempo, competição ferrenha e contínua atualização tecnológica e da área de estudos dão origem a uma fadiga institucional, que coloca a carreira como uma das mais estressantes do mercado.

Apesar dos relatos de sofrimento psíquico que emergem das pesquisas sobre prazer e sofrimento no trabalho docente (GUIMARÃES, 2005; MENDES et al, 2006; MANCEBO, 2007; CZEKSTER, 2007; MONTEIRO; 2008; NORONHA, ASSUNÇÃO e OLIVEIRA, 2008; GOMES e PEREIRA, 2009), o prazer que a atividade proporciona é uma constante no discurso sobre o sentido do trabalho de professor. Freitas (2007) enumera alguns pontos que remetem às alegrias do trabalho: liberdade de expressão; busca e contato com outros universos de ideias, de autores, de lugares e de temas que favorecem uma rica vida interior e a 
Vivências de prazer-sofrimento no trabalho do professor universitário: estudo de caso em uma instituição pública

aprendizagem; contato com os pares; o reconhecimento proporcionado pelas aulas, debates, conferências, publicações e participação em congressos; autonomia; e certo grau de liberdade relacionado a um maior controle sobre o seu tempo e ao conteúdo da prática docente.

Resta aos professores assumir este paradoxo: "o trabalho docente constitui-se num lugar contraditório que suscita, a um só tempo, sobretrabalho e prazer; assujeitamento e captura acrítica dos envolvidos para as novas demandas colocadas para a universidade, mas também espaço para invenções, pensamento e crítica" (MANCEBO, 2007, p. 79).

\section{METODOLOGIA DA PESQUISA}

Esta pesquisa é de natureza quantitativa e qualitativa. $\mathrm{O}$ método adotado foi o estudo de caso em uma IES pública localizada no município de Belo Horizonte-Minas Gerais, tendo como unidade de observação os professores do Curso de Pedagogia da Faculdade de Educação. O contato inicial com a instituição pesquisada foi feito por meio de reunião com a diretoria, que autorizou a realização da pesquisa desde que a IES não fosse identificada e definiu o período máximo de uma semana para a coleta dos dados. Nessa ocasião, optou-se por realizar a pesquisa no período noturno, por concentrar maior número de docentes.

A pesquisa se desenvolveu em duas etapas. $\mathrm{Na}$ primeira, foram aplicados os questionários com a escala de indicadores de prazer e sofrimento no trabalho (EIPST), constantes do Inventário sobre Trabalho e Riscos de Adoecimento (ITRA), desenvolvido e validado em estudos de Mendes e Ferreira (2007). Na segunda, foram realizadas as entrevistas semiestruturadas. A opção por aplicar apenas uma das quatro escalas que compõem o ITRA baseou-se na informação fornecida pela Coordenação de Curso de que os professores dispunham de pouco tempo na Instituição e que a aplicação de quatro questionários poderia inviabilizar a pesquisa.

Todos os docentes que passaram pela sala de professores foram convidados a participar da pesquisa. Nesse período observou-se que a sala é frequentemente um lugar de passagem e raramente um lugar de convívio. No período noturno, ela é frequentada não apenas pelos docentes daquele período, mas também por aqueles que ministram aulas à tarde e que permanecem na instituição após o trabalho e pelos professores da pós-graduação. Por este motivo, foram abordados professores de outros turnos que não apenas o noturno e também os da pós-graduação. 
A EIPST, de frequência tipo likert de 7 pontos, tem por objetivo avaliar a ocorrência das vivências de prazer-sofrimento nos últimos seis meses. Assim, $0=$ nenhuma vez e $6=$ seis ou mais vezes. A EIPST possui 32 itens e apresenta quatro fatores, sendo dois de itens positivos (realização profissional e liberdade de expressão) e dois de itens negativos (esgotamento profissional e falta de reconhecimento). Os resultados dos fatores positivos são interpretados de acordo com os seguintes critérios: acima de 4,0 = avaliação mais positiva, satisfatória; entre 3,9 e 2,1 = avaliação moderada, crítica; e abaixo de 2,0 = avaliação para raramente, grave. Os resultados dos fatores negativos são avaliados de forma inversa: acima de 4,0 = avaliação mais negativa, grave; entre 3,9 e 2,1 = avaliação moderada, crítica; e abaixo de 2,0 = avaliação menos negativa, satisfatória.

As entrevistas, em sua maior parte, foram realizadas via e-mail, atendendo à solicitação dos próprios docentes, pois havia se esgotado o prazo autorizado para a realização da pesquisa. Apenas duas entrevistas foram gravadas na instituição, com duração aproximada de 45 (quarenta e cinco) minutos. Para a construção do roteiro de entrevista, buscou-se inserir nas perguntas alguns dos itens constantes das demais escalas que compõem o ITRA (MENDES; FERREIRA, 2007), como contexto do trabalho, custo humano no trabalho (físico e afetivo), prazer e sofrimento e danos relacionados ao trabalho. Além disso, foi elaborado um índice explicativo das perguntas, para ajudar no esclarecimento de cada pergunta elaborada.

A análise dos dados quantitativos foi feita por meio de técnicas da estatística descritiva, média, desvio-padrão e teste "t" de diferença das médias, tratados pelo sistema SPSS (Statistical Package for Social Science). Os dados obtidos foram sistematizados sob a forma de quadros, tabelas e figuras. As entrevistas foram descritas qualitativamente com base na análise de conteúdo categorial (BARDIN, 1974). Os resultados de cada um dos instrumentos são integrados na discussão do trabalho e formam um conjunto de dados que, apesar de abordados metodologicamente de maneira distinta, fornecem subsídios para o estabelecimento de relações, do ponto de vista tanto empírico quanto teórico, no sentido de atender aos objetivos do estudo.

\subsection{Participantes da pesquisa}

A pesquisa, em sua fase quantitativa, foi realizada com uma amostra de 52 professores de um total de 115 pertencentes à Faculdade de Educação. Da amostra analisada na fase quantitativa, 35 representavam $81 \%$ dos 43 e atuavam no período noturno, sendo que 17 
Vivências de prazer-sofrimento no trabalho do professor universitário: estudo de caso em uma instituição pública

atuavam nos demais turnos. A amostra selecionada se constituiu, predominantemente, de docentes do gênero feminino $(65,38 \%)$. A faixa etária dos participantes situava-se, em sua maioria, entre 36 e 45 anos (46,14\%), sendo que cerca de 65,00\% tinham até 45 anos de idade. O estado civil predominante foi o casado $(44,23 \%)$, com ligeira vantagem em relação aos solteiros $(38,46 \%)$. A maioria possuía a titulação de mestre $(78,85 \%)$, era efetivada (51,92\%) e estava entre 6 e 10 anos na instituição (46,15\%), sendo que 76,00\% estavam há mais de cinco anos na instituição.

Tabela 1 - Distribuição dos participantes, por escolaridade, tipo de contrato de trabalho e tempo de serviço na instituição

\begin{tabular}{lllllllll}
\hline \multicolumn{1}{c}{ Escolaridade } & $\mathbf{N}$ & $\mathbf{\%}$ & Tipo de Contrato & $\mathbf{N}$ & $\mathbf{\%}$ & Tempo na Inst. & N & \% \\
\hline Doutorado & 3 & 5,77 & Designado & 3 & 5,77 & Até 5 anos & 12 & 23,07 \\
Mestrado & 41 & 78,85 & Efetivado & 27 & 51,92 & De 6 a 10 & 24 & 46,15 \\
Pós- graduação & 8 & 15,38 & Efetivo & 13 & 25,00 & De 11 a 15 & 10 & 19,24 \\
& & & Não respondeu & 9 & 17,31 & De 16 a 20 & 2 & 3,85 \\
& & & & & Acima de 20 & 4 & 7,69 \\
Total & & & & 52 & 100,00 & Total & 52 & 100,00 \\
\hline
\end{tabular}

Fonte: dados da pesquisa

$\mathrm{Na}$ fase qualitativa, foram entrevistados 9 professores que atuavam no período noturno. As idades variaram entre 36 e 45 anos e o tempo de permanência na instituição, entre 6 a 15 anos.

\section{ANÁLISE DOS DADOS}

Esta seção trata dos resultados apurados neste estudo. Inicialmente, serão apresentados os dados relativos à analise quantitativa do conjunto dos fatores da escala EIPST, com média e desvio-padrão. Na sequência, apresentam-se as tabelas com as maiores e menores médias dos itens de cada fator da escala, que foram analisados de forma articulada com os relatos das entrevistas e com a teoria.

A Tabela 2 permite constatar que os docentes apresentam vivências moderadas de sofrimento no trabalho, com predomínio das vivências de prazer, que receberam pontuações mais elevadas. O fator realização profissional recebeu média 4,12, seguido de liberdade de expressão, que recebeu média 4,16; e os fatores esgotamento profissional, 2,72; e falta de reconhecimento, 2,39 . 
Elena Fátima Vilela, Fernando Coutinho Garcia \& Adriane Vieira

Tabela 2 - Média, DP da EISPT

\begin{tabular}{lcc}
\hline FATOR & MÉDIA & DP \\
\hline Realização profissional & 4,12 & 1,54 \\
Liberdade de expressão & 4,16 & 1,81 \\
Esgotamento profissional & 2,72 & 1,99 \\
Falta de reconhecimento & 2,39 & 2,18 \\
\hline
\end{tabular}

Fonte: Dados da pesquisa

Os dados da Tabela 3 para o fator realização profissional revelam que os professores avaliam como itens mais positivos, orgulho pela profissão e identificação com suas atividades, dado que estes apresentaram as maiores médias: 5,04 e 4,88, respectivamente. O desvio padrão indica que identificação com as tarefas é o item que apresenta menor grau de variação nas respostas, enquanto satisfação, valorização, reconhecimento e motivação apresentam os maiores graus de variação.

Tabela 3 - Média, DP e moda do fator realização profissional

\begin{tabular}{lcc}
\hline ITEM & MÉDIA & DP \\
\hline Satisfação & 3,92 & 1,76 \\
Motivação & 3,94 & 1,67 \\
Orgulho pelo que faço & 5,04 & 1,28 \\
Bem-estar & 4,48 & 1,42 \\
Realização profissional & 4,63 & 1,52 \\
Valorização & 2,79 & 1,72 \\
Reconhecimento & 2,87 & 1,73 \\
Identificação com as minhas tarefas & 4,88 & 1,26 \\
Gratificação pessoal com as minhas atividades & 4,56 & 1,54 \\
Resultado geral & 4,12 & 1,54 \\
\hline
\end{tabular}

Fonte: Dados da pesquisa

De outro lado, os docentes avaliaram de forma negativa os itens valorização e reconhecimento, que se apresentam com as menores médias: de 2,79 e 2,87, respectivamente. A análise conjunta dos itens revela que os docentes têm orgulho pelo que fazem, identificam-se com as tarefas e se sentem realizados profissionalmente, o que gera a percepção de gratificação pessoal e de bem estar. No entanto, revelam a percepção de que falta valorização e reconhecimento, o que faz declinar o sentimento de satisfação e de motivação. É possível, portanto, afirmar que os docentes querem se sentir valorizados pela instituição e reconhecidos pela capacidade de realizar o que lhes foi confiado.

Dejours e Molinier (1989) consideram que os jogos de reconhecimento são capazes de transformar o sofrimento em prazer nas atividades de trabalho. Nesse sentido, o trabalho é entendido como constituinte do sujeito e central nos processos de subjetividade, devido à relação estreita que se estabelece entre a experiência na tarefa e as atividades perceptivas, sensoriais e cognitivas que se enraízam no corpo, conforme defendem Böhle e Milkau (1998). O 
Vivências de prazer-sofrimento no trabalho do professor universitário: estudo de caso em uma instituição pública

reconhecimento no trabalho implica a conquista da identidade no campo social. É graças ao reconhecimento do trabalho que os sujeitos podem estabilizar suas identidades e evitar o adoecimento mental ou somático (MOLINIER; DEJOURS, 1994; GERNET; DEJOURS, 2009).

Do ponto de vista histórico, a realização profissional pode ser entendida, segundo Tiger (1993), como um psicoprazer, pois está centrada na noção de indivíduo, que é relativamente recente na sociedade humana (HALL, 2003). Esta categoria de prazer está relacionada com a satisfação adquirida, entre outras fontes, pela própria atividade da pessoa, no uso de suas habilidades e de sua energia. Para o autor, esse tipo de prazer surge durante $\mathrm{o}$ desenvolvimento humano, a partir do toque, do contato e da comunicação. Portanto, o psicoprazer depende da existência de outras pessoas e do mundo real para surgir. A realização profissional é um tema que está ligado à relação do empregado com a organização e com todos aqueles que fazem parte do contexto.

Pesquisas realizadas por Mendes et al. (2006) e por Freitas (2007) revelam que a percepção de gratificação na carreira docente está fortemente associada à possibilidade de utilizar-se das faculdades mentais como um processo de criação artística, o que favorece a aprendizagem e possibilita um tipo de satisfação que faz superar a sensação de cançasso do final do dia, como exemplicam as falas de D4 e D7.

Adoro ser professora, de forma que estou sempre estimulada e motivada a ir para o trabalho. Ao final do dia, embora cansada, sinto-me realizada e alegre. (D4)

Normalmente, eu venho com certo entusiasmo. Acho que é essa questão assim da relação de gostar do trabalho, das atividades. Às vezes, a gente retorna pra casa um pouco cansada, em função do ritmo. (D7)

A carreira acadêmica na instituição pesquisada tem permitido, nos últimos anos, a articulação entre ensino e pesquisa, bem como intensificado a formação de novos pesquisadores e a publicação técnica, o que representa uma nova fonte de autorrealização, já que se trata de uma tarefa considerada nobre (FREITAS, 2007), por meio da qual se articulam planejamento, execução e contemplação dos resultados do trabalho (MENDES et al., 2006). É isso que "torna a produção do conhecimento fascinante" (D6).

Para que os grupos de pesquisa existentes se fortalecessem a IES passou a estimular os docentes a se titularem em cursos de mestrado e doutorado, o que é percebido como uma forma de reconhecimento.

A gente vê um fluxo grande de pesquisa. Então, isso eu acho muito bom. Eu trabalho muito, mas, em compensação, isso te dá uma realização. E, outra coisa, professores passaram a se titular mais. (D2) 
O fator liberdade de expressão, que também está relacionado ao prazer no trabalho, apresentou na fase quantitativa da pesquisa média ponderada, tendendo para alta, em todos os itens, uma vez que as duas menores são 3,67 para liberdade para negociar com a chefia o que precisa e 3,94 para cooperação com os colegas. Os itens que apresentaram médias maiores, na avaliação dos docentes, são liberdade para usar a criatividade, com 4,71, e liberdade para falar do trabalho com os colegas, com 4,48, conforme dados da Tabela 4. Note-se que o desvio-padrão é maior para o item liberdade para negociar com a chefia o que precisa, indicando maior grau de variação nas respostas.

Tabela 4 - Média, DP e moda do fator liberdade de expressão

\begin{tabular}{lcc}
\hline \multicolumn{1}{c}{ ITEM } & MEDIA & DP \\
\hline Liberdade para negociar com a chefia o que precisa & 3,67 & 2,31 \\
Liberdade para falar sobre o meu trabalho com os colegas & 4,48 & 1,85 \\
Solidariedade entre colegas & 4,21 & 1,73 \\
Confiança entre colegas & 3,87 & 1,75 \\
Liberdade para expressar minhas opiniões no local de trabalho & 4,31 & 1,65 \\
Liberdade para usar a criatividade & 4,71 & 1,41 \\
Liberdade para falar sobre o meu trabalho com as chefias & 4,06 & 1,99 \\
Cooperação entre os colegas & 3,94 & 1,79 \\
Resultado geral & 4,16 & 1,81 \\
\hline
\end{tabular}

Fonte: Dados da pesquisa

Apesar de os dados quantitativos indicarem uma minimização do sofrimento no trabalho neste fator, os dados das entrevistas permitem identificar algumas nuanças que podem explicar a pequena diferença de média entre os itens. Para a maioria dos entrevistados, o relacionamento social entre pares é o principal fator compensatório na relação prazer-sofrimento, um vez que "não há estrelismos e as pessoas difíceis de conviver são minoria" e, de maneira geral, prevalece o "diálogo, o respeito mútuo" (D4) e "a individualidade de cada um” (D1).

Essa minoria é identificada como "grupos que se articulam para a disputa de poder" (D2, D5, D6). Tal fato pode ser explicado pelo contexto institucional e pelas mudanças que aconteceram a partir do ano 2000, quando a categoria era constituída por apenas 14 professores efetivos e cerca de 90 professores designados. Os designados não podiam votar nem assumir cargos executivos e administrativos. Segundo relatos, vários professores designados eram parentes ou apadrinhados de efetivos, motivo pelo qual recebiam as melhores disciplinas e horários.

No final de 2007, o governo do estado instituiu a Lei Complementar 100, transformando os designados efetivados. Com isso, permitiu que eles gozassem de todos os benefícios dos efetivos, inclusive a aposentadoria pela Previdência Pública, ainda que permanecessem sem direito à estabilidade profissional. Nas eleições de 2008 para a Direção, um grupo de efetivos tentou vetar a participação dos efetivados, mas não conseguiu. A REAd I Porto Alegre - Edição 75 - N 2 - maio/agosto 2013 - p. 517-540 
Vivências de prazer-sofrimento no trabalho do professor universitário: estudo de caso em uma instituição pública

estratégia para se manterem no poder foi lançar uma chapa na qual o diretor era efetivo e o vice-diretor era efetivado. Ou seja, foi necessário fazer alianças.

O enquadramento foi realizado com base na situação funcional do servidor naquele ano. Com isso, os que estavam afastados para titulação ou por doença tiveram suas cargas horárias reduzidas. A partir de então, a prioridade na distribuição de disciplinas passou a ser realizada pelos critérios de cargo e de tempo de instituição. Segundo relatos, quando os professores se reuniam para realizar a distribuição das disciplinas o quadro de oferta já vinha preenchido com a carga horária dos efetivos, sem que precisassem estar presentes à negociação, provocando o descontentamento dos efetivados. A transformação dos designados em efetivos quase os igualou em termos de direitos trabalhistas. No entanto, aprofundou os conflitos, gerando um saudosismo em relação ao passado, quando as disputas eram menores.

Há vinte e tantos anos, quando eu entrei aqui era mais uma família. A gente partilhava mais. Atualmente, não é mais assim. Há grupos e não há aquele espírito da comunidade como antes. Eu não sei se isso aí é produto da própria sociedade. Eu sinto falta desse convívio mais comunitário (D2).

Este tipo de situação pode abalar a confiança entre os colegas $(3,87)$, conforme revelado na Tabela 4 no fator liberdade. Ao mesmo tempo, caracteriza o trabalho não apenas como uma atividade, mas também como uma relação social, que se desdobra em um mundo caracterizado por relações de desigualdade, de poder e de dominação (GERNET; DEJOURS, 2009). Trabalhar, de acordo com Dejours (2004), é engajar-se num mundo hierarquizado, ordenado e coercitivo, perpassado pela luta para a dominação. Assim, o real do trabalho não é somente o real do mundo objetivo da tarefa, mas também o real do mundo social. E, sem o reconhecimento, o sofrimento gerado pelo encontro com o trabalho permanece desprovido de significação (GERNET; DEJOURS, 2009; RENAULT, 2008).

Os professores efetivados têm garantida a carga horária da efetivação, devendo cumpri-la integralmente. Para isso, podem assumir atividades de docência, pesquisa e/ou extensão. Após a alocação de todos os professores (efetivos e efetivados), caso haja horasaulas não distribuídas, pode-se abrir processo seletivo para a designação de professores. Não obstante seu caráter excepcional, segundo os docentes, tornou-se situação rotineira na instituição, devido à quase ausência de concursos públicos.

Tal situação condiz com os achados de pesquisa de Mancebo (2007) que apontam a ocorrência da precarização do trabalho docente nas universidades públicas por meio da contratação temporária de professores substitutos, tanto para o atendimento do crescimento 
quantitativo e qualitativo de cursos e alunos como para a reposição paritária das vagas geradas por aposentadorias, óbitos, desligamentos voluntários e afastamento de docentes.

As dificuldades de negociação com as chefias, que aparece com a menor pontuação na mensuração do fator liberdade, são confirmadas pelos entrevistados, mas, ao mesmo tempo, são minimizadas quando eles a imputam "à sobrecarga de trabalho dos que assumem funções de coordenação e chefia (D4)". Os professores da instituição não têm organização sindical própria, existindo apenas reuniões esporádicas para tratar de questões específicas que afetavam a categoria, o que limita ou inibe a liberdade de expressão, "não porque haja censura ou boicote, mas porque num ambiente de trabalho permeado por insegurança profissional as manifestações pessoais devem ser dosadas e medidas, pois o risco de perder o emprego é sempre iminente" (D4). Aos poucos, o ensino vai se configurando como uma mercadoria, trazendo "no bojo o tecnicismo que reduz os problemas sociais a questões administrativas, esvaziando o campo social e político do debate educacional" (MARRACH, 2000, p. 52).

O possibilidade de o prazer superar o sofrimento está na liberdade para executar o trabalho (DEJOURS, 1992) e adaptá-lo às aspirações e competências do professor, que pode escolher os métodos e técnicas didáticas (FIDALGO; OLIVEIRA; FIDALGO, 2009) que julga mais adequados para atingir os objetivos de aprendizagem de sua disciplina. A autonomia neste caso é percebida como "relativa, mas mesmo assim positiva, porque pelo menos existe liberdade para elaborar o plano de ensino com base na ementa estabelecida" (D7).

No entanto, tal liberdade tem sido acompanhada, na atualidade, pela intensificação do trabalho docente, mediante a introdução de um sistema de avaliação baseado intensamente na produção de textos e publicações acadêmicas ditado pelo modelo Capes de avaliação a partir dos anos 1996/1997 (OLIVEIRA; FREITAS, 2008). Para Magalhães (2009), procurar as revistas A1 na avaliação da Capes e nela publicar o seu artigo tornou-se a mercadoria desejada pelos professores em suas práticas universitárias. Na moderna gestão universitária o controle se dá, fundamentalmente, por meio dos resultados, traduzido por metas para as publicações, o que faz a "direção dar as boas-vindas aos professores por meio de um cartaz, desejando também muitas produções" (D1) logo no início do semestre letivo.

Contudo, como advertem Chauí (2003) e Freitas (2007), a supervalorização da produtividade tem gerado também o descaso com a qualidade dos produtos gerados pelas pesquisas e certo incentivo ao irrelevante, desde que metodologicamente correto. Em outros termos, significa dizer que há pouca inovação e muita reprodução, quando o tempo de trabalho intelectual é acelerado e impede a maturação das produções. Pressionados, os 
Vivências de prazer-sofrimento no trabalho do professor universitário: estudo de caso em uma instituição pública

pesquisadores tendem a priorizar a quantidade de artigos publicados e o comparecimento a congressos e simpósios como forma de conservar o emprego, ascender na carreira e obter financiamento para suas pesquisas. É preciso provar continuamente que novos conhecimentos estão sendo alcançados, "uma vez que a avaliação deixou cada vez mais de ser feita pelos pares e passou a ser determinada pelos critérios da eficácia e da competitividade" (CHAUÍ, 2003, p. 10).

Falta ainda apontar as relações contraditórias que se estabelecem entre alunos e professores, fruto de uma gestão que cada vez mais se aproxima da lógica empresarial, a qual transforma o aluno em um consumidor de ensino (MARRACH, 2000; AQUINO, 1998) ou cliente, capaz de confrontar a autoridade do professor ao se comportar como "o dono da verdade e nos colocar em situações constrangedoras. Em qualquer situação de conflito, ele busca soluções com as instâncias superiores antes mesmo de tentar conversar com o professor" (D5).

A consequência é o aumento do esgotamento profissional, como se pode observar nos dados da Tabela 5, na qual se destaca a percepção de vivência de sofrimento moderado nos itens sobrecarga $(3,38)$, esgotamento emocional $(3,15)$ e estresse $(3,12)$, indicando o uso de estratégias defensivas.

Tabela 5 - Média, DP e moda do fator esgotamento profissional

\begin{tabular}{lcc}
\hline ITEM & MEDIA & DP \\
\hline Esgotamento emocional & 3,15 & 2,08 \\
Estresse & 3,12 & 2,04 \\
Insatisfação & 2,69 & 2,04 \\
Sobrecarga & 3,38 & 1,96 \\
Frustração & 2,75 & 2,04 \\
Insegurança & 2,40 & 1,99 \\
Medo & 1,56 & 1,74 \\
Resultado geral & 2,72 & 1,99 \\
\hline
\end{tabular}

Fonte: Dados da pesquisa

A sobrecarga é resultante da intensificação da atividade docente, que inclui cada vez mais novas demandas, como: participação em reuniões de grupos de pesquisa; participação em reuniões técnico-administrativas; representação em órgãos colegiados; participação em reuniões departamentais e com a Direção da Faculdade; e orientação e participação em bancas de monografias e trabalhos de conclusão de curso. "São essas demandas paralelas que tornam o ensino a rotina fatigante" (D7).

A dinâmica prazer-sofrimento fica ainda mais comprometida quando a organização do trabalho deixa de dar o suporte necessário à condução das atividades. Nesse momento, as queixas são dirigidas também ao mau funcionamento dos elevadores, limpeza das salas de aula e falta de REAd I Porto Alegre - Edição 75 - Nº 2 - maio/agosto 2013 - p. 517-540 
espaço físico para a realização das pesquisas. No período noturno, a situação é ainda mais precária, pois a lógica financista impõe a redução de custo por meio do corte de pessoal de apoio, "deixando indisponíveis setores importantes, como coordenação, secretaria e cantina. Em alguns momentos, nem o audiovisual (D1)".

Em situações de pressão e insatisfação, o custo afetivo passa a estar relacionado ao controle das emoções, expresso pela anulação dos comportamentos livres, como "passar raiva (D3)" ou "deixar de sorrir e manter o padrão clássico de educação (D1)", pois "apontar os erros, mesmo se disponibilizando para consertá-los, cria animosidade" (D1).

Para Abrahão e Sznelwar (2008), funcionar como um autômato sem manifestar alegria ou tristeza, sem reclamar o reconhecimento do próprio trabalho é considerado um indicador de profissionalismo. Entretanto, os sentimentos não manifestos ou invisíveis têm seus reflexos no modo de executar o trabalho e na saúde dos trabalhadores. No caso estudado, os processos de adoecimento têm envolvido distúrbios de sono, dores nas pernas, cansaço excessivo e, principalmente, uso intensivo da voz, coincidindo com os achados da pesquisa de Araújo, Sena, Viana e Araújo (2005). Como estratégia de mediação, alguns se utilizam da terapia, enquanto outros buscam minimizar e justificar os sintomas aparentes de adoecimento.

Medo é o sentimento menos presente na Tabela 4, bem como insegurança, o que se justifica por ser esta uma instituição pública, com garantia de emprego para os efetivos. No entanto, a situação é diferente para efetivados e designados, como D4, que atribui a falta de segurança quanto à manutenção de emprego não à competência e à capacidade profissional, "mas aos humores do mercado e aos humores dos gestores públicos, sempre interessados em desfazer tudo e começar do zero".

A análise quantitativa do fator falta de reconhecimento revela que os itens indignação $(3,42)$ e desvalorização $(2,87)$ contribuem para a percepção de vivência de sofrimento moderado no trabalho docente, conforme dados da Tabela 6. Os fatores que apresentaram as menores média foram inutilidade $(1,35)$ e discriminação $(1,71)$. 
Vivências de prazer-sofrimento no trabalho do professor universitário: estudo de caso em uma instituição pública

Tabela 6 - Média, DP e moda do fator falta de reconhecimento

\begin{tabular}{lcc}
\hline ITEM & MEDIA & DP \\
\hline Falta de reconhecimento do meu esforço & 2,62 & 2,34 \\
Falta de reconhecimento do meu desempenho & 2,62 & 2,33 \\
Desvalorização & 2,87 & 2,28 \\
Indignação & 3,42 & 2,27 \\
Inutilidade & 1,35 & 1,84 \\
Desqualificação & 1,96 & 2,06 \\
Injustiça & 2,60 & 2,25 \\
Discriminação & 1,71 & 2,08 \\
Resultado geral & 2,39 & 2,18 \\
\hline
\end{tabular}

Fonte: Dados da pesquisa

Os dados das entrevistas indicam que essas percepções estão associada principalmente à política de pessoal e à questão salarial, definidas pelos docentes como "precárias". Os pequenos avanços neste assunto referem-se ao recebimento de gratificações monetárias, que, no entanto, também adiam a adoção de uma política salarial de valorização da categoria.

O salário é pouco. Recebemos como professores do ensino médio. Não há um plano de carreira. De março para cá, depois de muita luta, temos uma gratificação, que nos diferencia dos professores do ensino médio. No entanto, por ser gratificação, se você tira licença perde tudo (D1).

Estudos de Kuenzer e Caldas (2009) mostram que as condições salariais dos docentes tem estreita relação com o processo de intensificação do trabalho e com o acúmulo e a diversificação de funções, produzindo a figura do professor tarefeiro, que se limita a repassar os conhecimentos elementares. No caso estudado, para auferirem melhores salários, os professores têm se submetido a extensas jornadas que incluem atividades em outras instituições de ensino. Essa é a condição que os possibilita "ter uma condição de vida minimamente decente" (D4).

A gratificação mencionada pelo entrevistado Dl está associada à Avaliação de Desempenho Individual (ADI) introduzida pelo estado a partir das propostas do "Choque de gestão". Anualmente, todos os servidores estáveis ocupantes de cargo de provimento efetivo e os detentores de função pública, no âmbito da Administração Pública direta, autárquica e fundacional do Poder Executivo (Decreto 43.672/03), são submetidos a tal avaliação para fins de promoção e progressão nas carreiras. Os resultados são utilizados como requisitos para o cálculo do adicional de desempenho e do prêmio por produtividade (Alves, 2006). No entanto, tal medida não é percebida pelos docentes desta pesquisa como um mecanismo real de mensuração do desempenho por discordarem dos critérios de avaliação, considerados "muito gerais", por desconhecerem "algumas metas que não fazem parte do acordo de resultados" e, 
principalmente, porque não envolve o aluno, considerado "como o mais capacitado para avaliar o professor".

Assim como Alves (2006), os entrevistados consideram que a ADI conduz à redução dos salários e à perda de vantagens associadas ao tempo de serviço, como quinquênios e biênios, que foram substituídos pelo desempenho no cálculo dos adicionais.

A avaliação quantitativa e objetiva do trabalho, segundo Dejours (2004), tornou-se um dos princípios da organização do trabalho. No entanto, as avaliações, às vezes sofisticadas, se comparadas à contribuição real daqueles que trabalham, conduzem ao absurdo de injustiças intoleráveis. Em verdade, não se sabe bem o que se avalia, mas, com certeza, não é o trabalho. Assim, a avaliação funciona, sobretudo, como um meio de intimidação e dominação.

Observa-se que os professores estão inseridos em um contexto repleto de ambiguidades. Eles devem oferecer um ensino de qualidade, em um sistema massificado e, muitas vezes, sem os recursos humanos e materiais necessários, recebendo baixos salários e um aumento de atividades, o que contribui, segundo Bizarro e Braga (2005), para um crescente mal-estar, reforçado pela perspectiva negativa que a sociedade vai construindo desses profissionais. Daí sobrevém a indignação, a exacerbação da individualização e a percepção de desvalorização e de falta de reconhecimento da hierarquia. A fragilização aumenta quando esses não podem sequer contar com a solidariedade dos colegas, que foi destruída pelas novas formas de gestão, em especial as que promovem a avaliação individualizada das performances, atreladas a novos critérios de qualidade, negando a subjetividade dos homens e mulheres que trabalham (GERNET; DEJOURS, 2009; VOSWINKEL, 2007).

Os docentes no Brasil formam um grupo profissional numeroso e composto por muitas mulheres (WERLE, 2005), o que provoca a diminuição de salários. A obtenção do título de mestre tem sido facilitada pelo aumento do número de cursos de mestrado e doutorado. Segundo dados da Coordenação de Aperfeiçoamento de Pessoal de Nível Superior (CAPES), de 2001 a 2010 a quantidade de pesquisadores formados por ano no País passou de 26 mil para 53 mil e o número de cursos de pós-graduação, de 1.500 para 2700. Com a massificação do ensino superior, o aluno vem adquirindo o estatuto de cliente, afetando as relações pedagógicas (MONTEIRO, 2008; MARRACH, 2000; GOMES e PEREIRA, 2009; AQUINO, 1998). A soma de esses fatores, segundo Hoyle (1987), contribui para a perda de prestígio da profissão. Nesse contexto, Bizarro e Braga (2005) defendem, com propriedade, que ainda que se reconheça a importância da missão desempenhada pelos professores, estes se constituem 
Vivências de prazer-sofrimento no trabalho do professor universitário: estudo de caso em uma instituição pública

em uma categoria profissional que deixou de usufruir uma reputação social elevada em função de um processo de inferiorização guiado por critérios econômicos.

\section{CONSIDERAÇÕES FINAIS}

Esta pesquisa, realizada com professores do Curso de Pedagogia da Faculdade de Educação de uma universidade pública de Belo Horizonte, Minas Gerais, teve por objetivo analisar as percepções de prazer-sofrimento dos docentes no exercício da profisssão.

No que se refere à relação dinâmica que se estabelece entre o prazer e o sofrimento no trabalho dos docentes, a análise dos dados quantitativos permite concluir que eles apresentam vivências moderadas de sofrimento no trabalho, com predomínio das vivências de prazer, que receberam pontuações mais elevadas.

A análise dos dados do fator realização profissional indica que o prazer dos docentes está associado ao orgulho pelo que fazem, à identificação com as tarefas e liberdade para executar o trabalho, à autonomia didática, ao uso da criatividade e à aprendizagem originada pelo próprio fazer. O sofrimento, por sua vez, advém da falta valorização e reconhecimento.

O fator liberdade de expressão apresentou médias ponderadas tendendo para altas para todos os itens. O prazer para esses docentes é consequência da liberdade para negociar com a chefia o que precisa e do relacionamento social entre os pares. No entanto, como revelam os dados qualitativos, o espaço de trabalho é preenchido por relações de poder e de dominação entre professores que se encontram em diferentes categorias profissionais (efetivos, efetivados e designados), o que lhes confere diferentes status, direitos e deveres, promovendo dispustas, frustações e demostivação.

O mal-estar e o sofrimento provocado pela precarização do trabalho dos docentes, tal como apontado nas pesquisas de Mancebo (2007), se revela nesta pesquisa associados a diversos fatores. O primeiro é a contratação temporária de professores substitutos (designados) para o preenchimento de vagas que deveriam ser preenchidas por meio de concurso público. $\mathrm{O}$ segundo fator é a intensificação da atividade docente, incluindo novas demandas (pesquisa, extensão, encargos administrativos e publicações científicas), que acabam por provocar sobrecarga, estresse e adoecimento. A falta de uma organização sindical que favoreça a liberdade de expressão é o terceiro fator. O quarto é a perda de autoridade de professor, que deve se relacionar com um aluno-cliente em um contexto que transforma o ensino em mercadoria. O quinto é a necessidade de lecionar em outras instituições de ensino como forma de complementação de salário. 
Como afirmam Gernet e Dejours (2009), nem todas as situações de trabalho são propícias ao reconhecimento e algumas profissões são de fato injustiçadas e desvalorizadas, em especial aquelas em que o reconhecimento dos pares é substituído pelo reconhecimento dos usuários; ou seja, os alunos. Quando as exigências tocantes ao desempenho são elevadas, quase impedindo o alcance da pontuação exigida nas avalições, elas são intepretadas pelos sujeitos como uma "recusa de reconhecimento", podendo gerar o superinvestimento na relação com o usuário, bem como a deterioração da reflexão coletiva sobre o trabalho e uma individualização da atividade individual originada na falta de solidariedade do coletivo.

No que se refere aos sintomas físicos e psicossociais relacionados ao trabalho, a análise dos dados qualitativos e qualitativos permite concluir que o uso de estratégias defensivas se torna necessário para lidar com o esgotamento emocional e o estresse gerado pelas situações mencionadas e que são agravadas pelo contexto do trabalho, como condições do ambiente físico, ausência de suporte organizacional para os trabalhadores docentes do período noturno, política de pessoal incipiente e ausência de valorização salarial da categoria. Os professores experimentam, ainda, custo físico, decorrente do uso intensivo da voz, distúrbios de sono, dores nas pernas, cansaço excessivo e controle das emoções, decorrente do medo da perda do emprego.

No caso estudado, o adoecimento está contido pelo uso eficaz das estratégias de mediação contra o sofrimento. A compensação ocorre quando os professores buscam maximizar as vivências de prazer como tentativa de atenuar as exigências do trabalho. A racionalização surge quando os docentes buscam justificar as situações desagradáveis do trabalho decorrente, principalmente, de controle das emoções e de custo emocional. A negação do sofrimento, por sua vez, decorre da tentativa de minimizar e justificar os sintomas físicos de adoecimento.

Para a IES pesquisada, o estudo demonstra a necessidade de dar transparência ao processo de contratação de professores, por meio da oferta de concursos públicos, e a importância de se implementar uma política de valorização salarial e social da profissão docente, bem como de prevenção dos riscos de adoecimento relacionados ao trabalho.

Ao governo, como responsável pela implementação de políticas para a educação superior e a gestão das IES públicas, é preciso lembrar que o primado pela educação superior não pode significar apenas o aumento do número de matrículas. Portanto, recomenda-se que tais políticas valorizem o trabalho docente como condição implícita para a manutenção do ensino superior público de qualidade, sem o que a precarização a que são submetidos ameaça repercutir no ensino e anular todo o empenho realizado. Os sentimentos de valorização e 
Vivências de prazer-sofrimento no trabalho do professor universitário: estudo de caso em uma instituição pública

reconhecimento, que medem o prazer no trabalho são encontrados em organizações que valorizam a democracia, a descentralização, a qualificação profissional, o coleguismo, a comunicação, o respeito e a equidade. Os indicadores de desempenho precisam se construídos coletivamente e deve-se levar em consideração que o sistema de ensino brasileiro é novo em comparação com o europeu e o americano. Portanto, as comparações devem ser relativizadas e contextualizadas, sem se colocar numa posição de colonizados pelos organismos internacionais.

Este estudo contribui para o avanço na investigação dos riscos de adoecimento presentes no contexto docente e fortalece a ideia do prazer como o objetivo do trabalhar. Reforça também a necessidade de aliar instrumentos de natureza quantitativa e qualitativa, principalmente quando se abordam questões subjetivas e de difícil confrontação pelos sujeitos, como o sofrimento no trabalho. As estratégias defensivas, como negação e racionalização, usadas para evitar a tomada de consciência do sofrimento, gerado são mais difíceis de persistirem em um contexto de intersubjetividade, como o que as entrevistas propiciam.

A limitação do estudo se apresenta pela aplicação de apenas uma das escalas que compõem o Inventário de Trabalho e Riscos de Adoecimento (ITRA), a escala EIPST, o que permitiu avaliar apenas a percepção de prazer e sofrimento no trabalho. Faz-se necessária, portanto, a realização de novas pesquisas com esta categoria profissional, com o objetivo de generalizar e aperfeiçoar o modelo teórico-metodológico aqui utilizado. Apesar dos avanços nos estudos da psicodinâmica, enquanto uma clínica do trabalho aplicada à gestão da organização do trabalho e às ações e políticas publicas de prevenção de doenças mentais ocupacionais, ainda existem lacunas a serem preenchidas para o estabelecimento do nexo causal entre trabalho e saúde mental. Sugere-se também a realização de estudos comparativos entre organizações públicas e privadas de ensino, entre gêneros e entre professores de áreas de ensino de com diferenças em relação ao prestígio social da profissão.

\section{REFERÊNCIAS}

ABRAHÃO, J. I; SZNELWAR, L. I. Entre a tarefa e a atividade: a dor do trabalhar. In: MENDES, A. M. (Org.). Trabalho e saúde: o sujeito entre emancipação e servidão. Curitiba: Juruá, 2008.

ALVES, A. C. T. A. As reformas em Minas Gerais: choque de gestão, avaliação de desempenho e alteração no trabalho docente. VI Seminário da REDESTRADO Regulação Educacional e Trabalho Docente, UERG - Rio de Janeiro, p. 1-13, 2006.

REAd I Porto Alegre - Edição 75 - N 2 - maio/agosto 2013 - p. 517-540 
Diponível em:<

http://www.fae.ufmg.br/estrado/cd_viseminario/trabalhos/eixo_tematico_1/as_reformas_em_ mg_choqeu_gestao.pdf. Acesso em: 25 jan. 2011.

AQUINO, J. G. A violência escolar e a crise da autoridade docente. Cadernos Cedes, Campinas/São Paulo, ano XIX, n. 47, p. 7-19, 1998.

ARAUJO, T. M; SENA, I. P; VIANA, M. A; ARAUJO, E. M. Mal-estar docente: avaliação de condições de trabalho e saúde em uma instituição de ensino superior. Revista Bahiana de Saúde Pública, Salvador, v.29, n.1, p.6-21, 2005.

BARDIN, L. Análise de conteúdo. Liboa: Edições 70, 1977.

BIZARRO, R.; BRAGA, F. Ser professor em época de mal-estar docente. Revista da Faculdade de Letras, II série, vol. XXII, Porto, p. 17-27, 2005.

BÖHLE, F.; MILKAU, B. De la manivelle à l'ecran. L'evolution de l'experience sensible des ouvries lors des changements techonoloques. Paris: Éditions Eyrolles, 1998.

BRASIL. Lei Complementar 100/2007, de 05/11/07. Disponível em:

$<$ www.apaeminas.org.br/arquivo.phtml?a=10642 > . Acesso em 16 nov. 2010.

CHAUÍ, M. A universidade pública sob nova perspectiva. Revista Brasileira de Educação, Rio de Janeiro, n. 24, p. 5-15, 2003.

COLE, M.; WALKER. S. (ed.). Teaching and stress. Milton Keynes: Open University Press, 1989.

CZEKSTER, M. D. Sofrimento e prazer no trabalho docente em Escola Pública. 2007. 152 f. Dissertação (Mestrado em Administração) - Programa de Pós-graduação em Administração da Universidade Federal do Rio Grande do Sul, 2007.

DAVEZIES, P. Éléments pour une clarification des fondements épistemologique d'une science du travail. Communication au Colloque National de la Société Française de Psychologie, Clermont-Ferrand, p. 6-12, 1991.

DE BRANDT, J.; DEJOURS, C.; DUBAR, C. La France malade du travail. Paris: Bayard, 1995. 
Vivências de prazer-sofrimento no trabalho do professor universitário: estudo de caso em uma instituição pública

DEJOURS, C. Aspects psychopathologiques du travail. In: LÉVY-LEBOYER, C.;

SPÉRANDIO, J.-C. Traité de psychologie du travail. Paris: PUF, 1987. p. 729-748.

DEJOURS, C. ; MOLINIER, P. De la peine au travail. Autrement. Série Mutations, 142, p. 138-151, 1989.

DEJOURS, C. A loucura do trabalho: estudo de psicopatologia do trabalho. 5. ed. São Paulo: Cortez-Aboré, 1992.

DEJOURS, C. Addendum da psicopatologia à psicodinâmica do trabalho. In: LANCMAN, S; SZNELWAR, L. I. (Orgs.). Christophe Dejours: da psicopatologia à psicodinâmica do trabalho. Rio de Janeiro: Fiocruz, Brasília: Paralelo 15, 1993/2008.

DEJOURS, C. Entre sofrimento e reapropriação: o sentido do trabalho. In: LANCMAN, S; SZNELWAR, L. I. (Orgs.). Christophe Dejours: da psicopatologia à psicodinâmica do trabalho. Rio de Janeiro, Fiocruz; Brasília. Paralelo 15. 1994/2008.

DEJOURS, C. Subjetividade, trabalho e ação. Revista Produção Online, Florianópolis, v. 14, n. 3, p. $27-34,2004$.

DEJOURS, C. Prefacio. In: Mendes, A. M (Org.). Psicodinâmica do trabalho: teoria, método e pesquisas. São Paulo: Casa do psicólogo, 2007.

ESTEVE, J. M. EI malestar docente. Barcelona: Laia, 1987.

FIDALGO, F.; OLIVEIRA, M. A. M.; FIDALGO, N. L. R (Orgs.). A intensificação do trabalho docente: tecnologias e produtividade. Campinas: Papirus, 2009.

FIDALGO, F.; OLIVEIRA, M. A. M.; FIDALGO, N. L. R. Apresentação. In: FIDALGO, F.; OLIVEIRA, M. A. M.; FIDALGO, N. L. R (Orgs.). A intensificação do trabalho docente: tecnologias e produtividade. Campinas: Papirus, 2009.

FREITAS, M. E. A carne e os ossos do ofício acadêmico. Revista Organização \& Sociedade, Salvador, v. 14, n. 42, p. 187-191, 2007.

GERNET, I.; DEJOURS, C. Évaluation du travail et reconnaissance. Nouvelle Revue de Psychosociologie, Paris, v. 8, n. 2, p. 27-36, 2009. 
GOMES, C. A.; PEREIRA, M. M. A formação do professor em face da violência das/nas escolas. Cadernos de Pesquisa, Belo Horizonte, v. 39, n. 136, p. 201-224, 2009.

GOMES, R. Culturas de escola e identidades dos professores. Lisboa: Educa, 1993.

GUIMARÃES, F. A. L. Realização profissional, prazer e sofrimento no trabalho e valores: um estudo com professores de nível superior. 2005. 147f. Dissertação (Mestrado em Psicologia) - Programa de Pós-Graduação em Psicologia da Universidade Federal de Uberlândia, 2005.

HALL, S. A identidade cultural na pós-modernidade. 8. ed. Rio de Janeiro: DP\&A, 2003.

HOYLE, E. Teachers' social backgrounds. In: The international encyclopedia of teaching and teacher education, 1987, pp. 593-610.

KUENZER, A. Z; CALDAS, A. Trabalho docente: comprometimento e desistência. In: FIIDALGO, F.; OLIVEIRA, M. A. M.; FIDALGO, N. L. R. (Orgs.). A intensificaçãa do trabalho docente: tecnologias e produtividade. Campinas: Papirus, 2009.

LHUILIER, D. Filiations théoriques. In: LHUILIER, D. Cliniques du travail. Toulouse: Ères, 2007, p. 21-57.

MANCEBO, D. Trabalho docente: subjetividade, sobreimplicação e prazer. Psicologia: Reflexão \& Crítica, Porto Alegre, v. 20, n. 1, p. 77-83, 2007.

MARRACH, S. A. Neoliberalismo e educação. In: SILVA JUNIOR, C. A. da et al. Infância, educação e neoliberalismo. 2. ed. São Paulo: Cortez, 2000.

MARTÍNEZ, D. I. V.; KOHEN J. Salud y trabajo docente: tramas do malestar en la escuela, Buenos Aires: Kapelusz, 1997.

MENDES, A. M; FERREIRA, M. C. Inventário sobre trabalho e riscos de adoecimento ITRA: instrumento auxiliar de diagnóstico de indicadores críticos no trabalho. In: MENDES, A. M. (Org). Psicodinâmica do trabalho: teoria, método e pesquisas. São Paulo: Casa do Psicólogo, 2007.

MENDES, L. et al. A dialética prazer/desprazer no trabalho: vivências de significado e sofrimento no trabalho de professor universitário. In: ENCONTRO DA ASSOCIAÇÃO NACIONAL DE PÓS-GRADUAÇÃO E PESQUISA EM ADMINISTRAÇÃO, 30., 2006, Salvador, Anais... Salvador: Anpad, 2006.

REAd I Porto Alegre - Edição 75 - N 2 - maio/agosto 2013 - p. 517-540 
Vivências de prazer-sofrimento no trabalho do professor universitário: estudo de caso em uma instituição pública

MOLINIER, P.; DEJOURS, C. Le travail comme enigma. Sociologie du Travail, Paris, v. 36, p. 35-44, 1994.

MONTEIRO, H. R. Construindo saúde: a dimensão coletiva do trabalho docente. Salto para o Futuro. Saúde do professor em questão. Edição Especial, ano XVIII, Boletim 19, outubro de 2008, p. 3-10. Disponível em: <http://www.tvbrasil.org.br/saltoparaofuturo/boletins.asp>. Acesso em: 25 jan. 2010.

NORONHA, M. M. B.; ASSUNÇÃO, A. A.; OLIVEIRA, D. A. O sofrimento no trabalho docente: o caso dos professores da rede pública de Montes Claros, Minas Gerais. Trabalho, Educação, Saúde, v. 6, n. 1, p. 65-85, 2008.

OLIVEIRA, E. S. G. O. Mal-estar docente como fenômeno da modernidade: os professores no país das maravilhas. Revista Ciências \& Cognição, Rio de Janeiro, v. 7, p. 27-41, 2006. Disponível em: <www.cienciasecognicao.org>. Acesso em: 20 dez. 2009.

OLIVEIRA, M. A. M.; FREITAS, M. V. T. Políticas contemporâneas para o ensino superior: precarização do trabalho docente? Revista Extra-Classe, Belo Horizonte, n.1, v. 2, ago. 2008. Disponível em: <www.sinprominas.org.br>. Acesso em: 20 dez. 2009.

RENAULT, E. Souffrances socials. Philosophie, psychologie et politique. Paris: La Découverte, 2008.

STOBAUS, C. D; MOSQUERA, J. J; SANTOS, B. S. Grupo de pesquisa mal-estar e bemestar na docência. Revista Educação - PUCRS, Porto Alegre, v. 30, p. 259-272, out. 2007. Edição especial.

TIGER, L. A busca do prazer. Rio de Janeiro: Objetiva, 1993.

VOSWINKEL, S. L'admiration sans apréciation. Les paradoxes de la double reconnaissance du trabail subjectivisé, Travailler, Paris, n. 18, p. 59-87, 2007.

WERLE, F. O. C. Práticas de gestão e feminização do magistério. Cadernos de Pesquisa, São Paulo, v. 35, n. 126, p. 609-634, 2005. 